\title{
The Design Education of the New Era Urgent Needs to Cultivate Engineering Ethics Consciousness
}

\author{
Liu Wenming ${ }^{\mathrm{a}}$ \\ ${ }^{1}$ School of Design and Art, Shenyang Jianzhu University, 110168 Shenyang, Liao Ning, China
}

\begin{abstract}
By expounding the inseparable relationship between design and engineering ethics, and comparing the current situation of the development of engineering ethics education at home and abroad, we find that there is a big gap between China's design professional education and western developed countries in the training of engineering ethics awareness. It is proposed that the domestic engineering profession, especially the design profession, is in urgent need of cultivating the designer's engineering ethic awareness, so as to improve the professionalism of the design talents and promote the better development of our country's design education.
\end{abstract}

\section{Introduction}

With the rapid development of China's economy, 'Made in China' in the development is gradually undergoing industrial transformation to "Created in China" and "China's Intellectual Creation", resulting in a growing demand for design talents. According to relevant data, in recent years, the design profession has become one of the most popular majors in China's colleges and universities. China has become a big country in higher design education, and the state has increased the training of design and innovation talents. At the same time, accompanied by rapid economic development and intensive construction, a large number of engineering projects and design works that lack ethics and morality have emerged. Based on this status, design education calls for ethical awareness. At present, compared with Western developed countries, there are many aspects such as the lack of teaching resources, backward curriculum design, unreasonable professional construction, and so on. Especially in the training of engineering ethical awareness, there is a big gap, which affects the degree to a certain extent. The overall level of personnel training. In-depth exploration of the designer's ethical awareness in design education in China will play a positive and critical role in the sustainable scientific development of design education.

\section{Design and engineering ethics are inseparable}

People generally attribute ethical issues to philosophical issues, incorporating the dimension of ethics into the dimension of philosophy. However, the dimensions involved in ethics are exceeded the scope of philosophy. The ethical dimension we talked is the way of people 'do something right', but "do something right" is not just an

\footnotetext{
*Corresponding author: a Liu Wenming, 83373734@qq.com
}

ethical issue, it is also a practical issue. What is worth noting that ethical issues show certain particularities and that is also closely related to the specific engineering context in the specific engineering practice. We can fully understand the project as a design process.

Xiao Ping's definition of engineering ethics in the book Engineering Ethics (1999) said: "Engineering ethics is a systemic research and academic construction based on engineering activity as a research object and ethical phenomena." The aim is to help those people who are facing engineering decision-making, engineering design and construction project management to establish clear social responsibility awareness, social value vision and the moral sensitivity to the comprehensive effects of the project, so that they can soberly facing all kinds of conflicts of interests and values in their professional activities, they can make judgments and decisions that is in the common interests of people and long-term development they need, They also can create high-quality products and services for the society with a rigorous scientific attitude and practical professionalism. ${ }^{[1]}$

Design is a kind of creative behavior, which takes the inspiration of the mind conceived through the conception, formation, refinement, scrutiny, and refinement, then conveyed and represented in a form that people can perceive. The plan and behavior that can translate any idea into a physical object is understood as design. Engineering activities is a process of designing such thoughts and behaviors, so it can be understood that design is the essence of engineering.

Engineering is the art of harnessing the power derived from nature for human use and for the convenience of mankind. The project is produced or manufactured according to the design, so we can say design is the soul of project. The relationship between design and engineering is extended to social relations, that is, the executors of the project must be implemented to specific 
people. The goals of designers and engineers are the same, and the behaviors are also consistent. The ultimate goal is to turn these thoughts into action. It can also be said that the real engineer is the designer. Because of this, we have to pay due attention to the inevitably problems about design and engineering ethics.

\section{The development of engineering ethics education in foreign design education}

The development of engineering ethics in Occident and its impact on design education is earlier. In 1852, the American Society of Civil Engineers (ASCE) was founded, then there were many engineering associations in the United States were established one by one and started the gradual professionalization process.

In the early 20th century, the United States began to formulate more formal rules of professional ethics in 1914. ASCE adopted an ethical code in September 1914. During the first 30 years of the 20th century, the engineering ethics code became the most important part of various engineering organizations when carrying out engineering activities. Until affected the related area of the education of engineering and design.

The ethical issues in engineering practice had become a matter of concern after World War II. The impressive building capacity and destructive power of the project caused engineers to rethink profoundly and pay attention to environmental issues and their own ethical responsibilities. The Scientist Communications of the United States and the Federation of American Scientists special publications had published and some relevant institutes also were established.

The fatal casualties caused by the poor design of the 1972 Ford Pinto vehicle caused public rethinking, this incident prompted engineers to re-examine the law with new mandatory requirements. Directly led to the birth of engineering ethics in North America. The Accreditation Board for Engineering and Technology (ABET) gradually began to take the content of engineering ethics education as one of the contents of engineering degree certification. Until about 2000, the ABET provided a new set of 11 certification standards for college graduates. This prompted engineering ethics, at least nominally, to become an important part of engineering education. At that time, many colleges and universities in the United States began to set up engineering ethics courses and added ethical training to the learning requirements of universities. At this time, students were required to have the ability to understand ethical issues and learn how to solve the ethical dilemmas when they encountered at work. In the late 1970s, engineering ethics was established as a discipline, It was "consisting of the responsibilities and rights of those engaged in engineering, as well as the ideals and personal promises that were expected in the project", the occupational ethics regulations of the engineering communities in the West. Constitutes the main content of engineering ethics. The United States, France, Germany, Japan, Britain and other developed countries have successively carried out engineering ethics education. ${ }^{[2]}$
After the 1990s, strengthening engineering ethics education and improving the social responsibility of engineers and other engineering practitioners have become an important aspect of engineering education. Since 1994, the American Society of Engineering Education (ASEE) and the National Science Foundation (NSF) published some relevant reports about engineering education reform, respectively, calling for strengthening engineering ethical education in view of the ethical issues faced by engineers. Since 1996, the registered professional engineer examination has incorporated engineering ethics into the "Engineering Foundation" exam. Therefore, engineering ethics education has been incorporated into the system of education certification and project certification.

\section{Development and Status of Engineering Ethics Education in Design Education in China}

The engineering ethics education which belong to design education started comparatively late in China. At the early stage it was subordinated to ideological and political education. Engineering ethics education is not a simple ideological and political education. They are two totally different kinds of things

The engineering ethics education of the 1990s began to attract the attention of relevant domestic scholars. Some scholars introduced the situation of engineering ethics education in the United States, Germany, Japan, and then published articles to discuss the significance of engineering ethics education, and called for engineering ethics in China's education. Tsinghua University, Dalian University of Technology, Beijing Institute of Technology, Xi'an Jiaotong University and some other science and engineering colleges started to offer courses that relate engineering regulations and case studies.

After entering the 21 st century, engineering ethics education aroused considerable interest in government and all circles, especially in higher education, Macrolayout engineering ethics education had become a consensus. At present, there is still a big gap between China's engineering ethics education and foreign advanced countries. Borrowing textbooks from abroad, such as Engineering Ethics, Engineering Ethics: Concepts and Cases these American books. By contrast, we have few professional textbooks, the foundation of demonstration teaching materials is weak. At the same time, the engineering ethics education curriculum system is weakened. The ethical courses of engineering education are compulsory courses in foreign country, even more important than engineering education itself. The establishment of engineering ethics education courses in colleges and universities is the prerequisite for setting up engineering education courses. But in our country, the vast majority of local engineering colleges neglected engineering ethics education. Some colleges and universities do not even offer related courses. Many schools only set up engineering ethics courses as public elective courses or even public elective courses. The schools which take engineering ethics education as a 
required course, lack the curriculum system construction, set up only basic elementary courses, and failed to carefully select excellent teaching content. Engineering ethics education is still not paid due attention until now. ${ }^{[3]}$ Especially in China's design education, the cultivation of engineering ethical awareness has not been mentioned yet.

\section{As a designer of a new era, it must have a sense of engineering ethics and social responsibility.}

As a profession, designers have been given a nobler historical mission in the new era. Not only are they able to design new products with novel styles and complete functions, but also achieve the purpose of stimulating consumption and pursuing profit maximization through sales of these products. They also take on some social responsibility. Now, simple and basic design will no longer be a problem to designers. It is especially important for designers to abide by ethical norms and ethical standards in their work. The opposition, criticism and transcendence of styles indicate that the professional consciousness of designers has been improved and matured. The problems faced by designers are no longer the problems of form or function, and the ethical awareness of engineering as a designer's essential professional qualities should be generally available in the designer community.

Designers should be bold in taking ethical responsibility not just having a sense of engineering ethic. Ethical responsibility includes three parts, A, professional ethical responsibilities which include role responsibilities, duty responsibilities and negligence responsibilities; B, social ethical responsibilities, designers should take more extensive social ethical responsibilities not just responsible for product, company, or loyalty; C, environmental ethical responsibility, designers need to understand the intrinsic value of the environment, rather than the environment as a free product, we must always implement the concept of "sustainable development". The significance of cultivating the designer's engineering ethic awareness lies not only in stimulating the designer's inner sense of responsibility and morality, but also directly putting this kind of engineering ethics consciousness into practice.

\section{The cultivation of awareness of engineering ethic contributes to better development of design education}

The ultimate goal of design education is to cultivate outstanding design talents. An excellent design talent should not only have comprehensive and complete design capabilities, but also need a sense of engineering ethics and social responsibility. The training of engineering ethics in design education can help to achieve the following development goals:

(1) Helps to form an ethical code for design professions as soon as possible

Design professional ethical standards refer to the code of conduct that designers should be following when they are facing ethical issues, and provide a basis for designers to solve ethical issues. Design professional ethical standards are dynamic. Different social development stages, design ethics norms only reflect the mainstream social values and ethical ideological norms at the time, and therefore have important guiding significance for designers' design practice. Through the cultivation of ethical awareness, it is bound to promote the formation and improvement of design professional ethics.

(2) Helps cultivate designer's engineering ethical awareness and responsibility

Through systematic study and practice, we can gradually cultivate awareness of engineering ethics. Designers who lack a sense of engineering ethics may unconsciously make ethical decisions and actions. Training the designer's awareness of engineering ethic is to increase the designer's sensitivity to engineering ethical issues, increase understanding of ethical issues, and place emphasis on the conscientiousness and initiative of various ethical issues in design practice. This enhances the designer's sense of professional ethics, social moral responsibility and environmental moral responsibility.

(3) Helps enhance designers' ability to make engineering ethics decisions

The decision-making ability of engineering ethics means that in the face of ethical dilemmas, it is difficult to make judgments based only on the ethical guidelines of the project. Designers need to have more sophisticated rational decision-making capabilities. In contemporary design practice, both technical issues and interest relationships are unprecedentedly complicated. Ethical decision-making capabilities have become one of the necessary conditions for dealing with ethical issues.

\section{Conclusion}

The design education in the new era must shoulder higher historical mission and social responsibility. At present, China's design education has not paid attention to cultivating designers' ethical awareness of engineering. Design education calls for engineering ethic, it is imperative to cultivate designers' awareness of engineering ethic in design education.

\section{References:}

1. Wu Jin, Qin Yan. The Core Elements Selection of Engineering Ethics Education Based on AHP and Entropy Method [J]. Value Engineering, 2015,34(14):195-199.

2. He Jing. Moral Philosophy Analysis of the Generation of Engineering Ethics [J]. Morality and Civilization, 2013(01):121-125.

3. Li Changling, Yu Jianjun, Zhang Mengge, Liu Jianxin. Investigation Report on Engineering Ethics Education in Local Engineering Colleges [J]. Industry 
and Technology Forum, 2013,12(13): 185-186.

4. Dong Wei. Reflections on the Cultivation of Environmental Art Design Talents in Colleges and Universities from the Perspective of Ethics [J]. Course Education Research, 2012, 9

5. Zhang Fuye. How to Make Ethical Ideas Become the Designer's Consciousness [J]. Art Observation, 2003,
6

6. Zhao Weijun. Ethic Dimension and Designers' Responsibility in Modern Design [J]. Hundred Schools in Arts, 2014, 2

7. Li Zhengfeng, Chong Hangqing, Wang Qian. Engineering ethics. Beijing: Tsinghua University Press, 2016 